Projet de renforcement de la surveillance de la rage en Côte d'Ivoire RAB42

Rapport préliminaire du projet - Janvier - décembre 2015

Présenté par Professeur Tiembré Issaka, Investigateur coordonnateur

10 Aout 2016

\title{
I. Résultats
}

\section{II.1. Point sur les cas de rage humaine}

II.1.1. Qualité des prélèvements

Tableau I : Répartition des prélèvements selon la qualité, Projet RAB42, 2015

\begin{tabular}{|l|l|l|}
\hline Qualité du prélèvement & Effectif & Pourcentage \\
\hline Non prélevés & 6 & 35,3 \\
\hline Prélèvements Conformes & 5 & 29,4 \\
\hline Prélèvements non Conformes & 6 & 35,3 \\
\hline Total & 17 & 100 \\
\hline
\end{tabular}

\section{II.1.2. Epidémiologie descriptive des cas}

- Répartition géographique des cas

Au cours de l'année 2015, sur les dix-sept (17) cas suspects de rage humaine détectés 5 ont été confirmés par l'IPCI soit 29,4\% dont la répartition est dans la figure 1. 


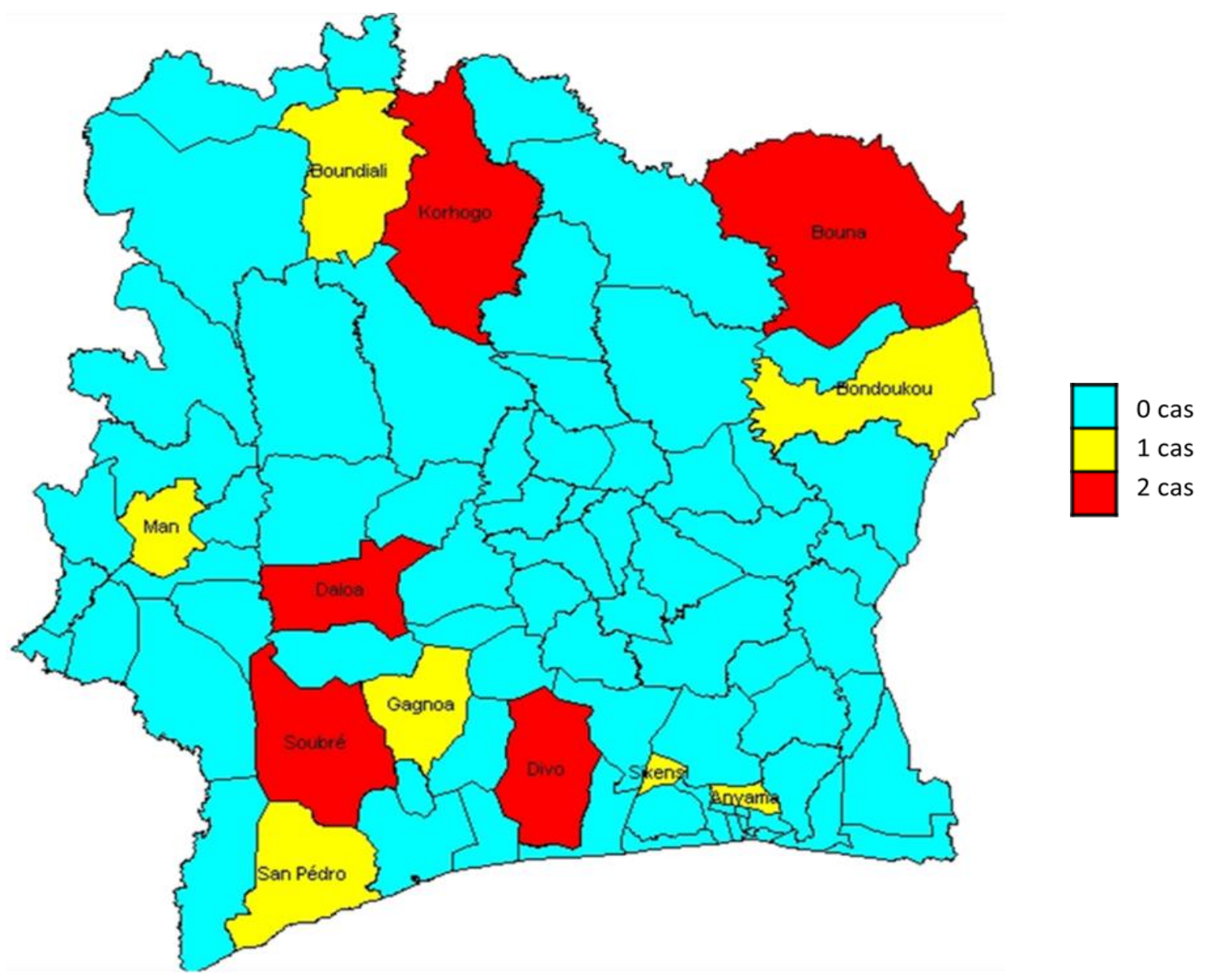

Figure 1 : distribution des cas suspects de rage humaine, Cote d'Ivoire, 2015

Tableau II : Répartition des patients selon la profession

\begin{tabular}{|l|l|l|}
\hline Profession & Nombre & Pourcentage \\
\hline Sans profession & 6 & 35,30 \\
\hline Ménagère & 5 & 29,40 \\
\hline Elevé & 3 & 16,65 \\
\hline Planteur ou cultivateur & 3 & 16,65 \\
\hline Total & $\mathbf{1 7}$ & $\mathbf{1 0 0}$ \\
\hline
\end{tabular}


Tableau III : Répartition des personnes exposées à la rage, 2015 par tranche d'âge.

\begin{tabular}{|l|l|}
\hline Tranche d'âge & Nombre de cas d'exposition \\
\hline $0-5$ ans & 1505 \\
\hline $6-15$ ans & 4348 \\
\hline$>15$ ans & 5064 \\
\hline Total & 10917 \\
\hline
\end{tabular}


Tableau IV : Données des cas de rage humaine de Janvier à décembre 2015, projet RAB 42

\begin{tabular}{|c|c|c|c|c|c|c|c|c|c|}
\hline $\begin{array}{l}\text { Semaine de } \\
\text { Notification }\end{array}$ & $\begin{array}{l}\text { Age } \\
\text { (Année) }\end{array}$ & Sexe & Profession & Animal & Date expo & Localité & $\begin{array}{l}\text { Prélèvement } \\
\text { échantillons }\end{array}$ & $\begin{array}{l}\text { date de } \\
\text { décès }\end{array}$ & $\begin{array}{l}\text { District } \\
\text { sanitaire }\end{array}$ \\
\hline 2 & 24 & $\mathrm{~F}$ & Ménagère & chien & $01 / 12 / 14$ & Logoualé & oui: 1,2 et 3 & $10 / 01 / 15$ & MAN* \\
\hline 4 & 5 & $M$ & Néant & chien & $25 / 12 / 14$ & $\begin{array}{l}\text { Koraleara } \\
\text { (Korhogo) }\end{array}$ & oui: 2 et 3 & $23 / 01 / 15$ & Korhogo* \\
\hline 12 & 60 & $\mathrm{~F}$ & Ménagère & chat & $26 / 02 / 15$ & $\begin{array}{l}\text { Progreagui } \\
\text { (Méagui) }\end{array}$ & oui: 1 & $24 / 03 / 15$ & Soubré** \\
\hline 13 & 9 & $\mathrm{~F}$ & Néant & chien & 01/01.15 & $\begin{array}{l}\text { Gadago (grand- } \\
\text { zatri) }\end{array}$ & oui: 1 & $22 / 03 / 15$ & Soubre** \\
\hline 15 & 73 & $M$ & Planteur & chien & $25 / 02 / 15$ & Sikensi & Non & $11 / 04 / 15$ & Sikensi*** \\
\hline 15 & 60 & $\mathrm{~F}$ & Ménagère & chat & $14 / 03 / 15$ & Anyama & Oui: 1 et 2 & $18 / 04 / 15$ & Anyama* \\
\hline 20 & 8 & M & élève & Chien & $08 / 04 / 15$ & Hiré & Non & $13 / 05 / 15$ & DIVO*** \\
\hline 21 & 34 & $M$ & Planteur & Chien & $24 / 02 / 15$ & Gagnoa & Non & $24 / 05 / 15$ & Gagnoa*** \\
\hline 22 & 15 & $M$ & élève & Chien & $01 / 12 / 14$ & San-pédro & Oui: 2 & $27 / 05 / 15$ & San-Pédro*** \\
\hline 25 & 17 & $\mathrm{~F}$ & Ménagère & chiot & $13 / 04 / 15$ & Daloa & Oui: 1 et 2 & $21 / 06 / 15$ & Daloa* \\
\hline 31 & 4 & $F$ & Néant & Chien & $15 / 07 / 15$ & Divo & Oui: 1 et 2 & $24 / 07 / 15$ & Divo** \\
\hline 32 & 4 & $M$ & Néant & Chien & inconnu & Boundiali & Oui: 2 & $03 / 08 / 15$ & Boundiali* \\
\hline 38 & 9 & $\mathrm{M}$ & élève & chien & $16 / 08 / 15$ & Gogobio & Oui: 1 et 3 & 20/09/15 & Daloa** \\
\hline 43 & 19 & $\mathrm{~F}$ & Ménagère & chien & $30 / 09 / 15$ & Wonanfanyon & Non Prélevé & $21 / 10 / 15$ & Bouna*** \\
\hline
\end{tabular}


Clés de couleur : cas confirmés par l'IPCI ; prélèvement non conforme ; cas non prélevés.

Clés d'échantillons : 1 = salive $; 2$ = peau ; 3 = urines

$\mathrm{F}$, femelle ; $M$, mâle; $\mathrm{N}$; non enregistré 